\title{
A lipid-based parallel processor for chemical signals
}

\author{
Idil Cazimoglu, Michael J. Booth*, Hagan Bayley* \\ Chemistry Research Laboratory, University of Oxford, Oxford, OX1 3TA, UK. \\ *Corresponding authors, email: hagan.bayley@chem.ox.ac.uk or michael.booth@chem.ox.ac.uk
}

\begin{abstract}
A key goal of bottom-up synthetic biology is to construct cell- and tissue-like structures. Underpinning cellular life is the ability to process several external chemical signals, often in parallel. Until now, however, cell- and tissue-like structures have only been constructed with one signalling pathway. Here, we construct a dual-signal processor from the bottom up in a modular fashion. The processor comprises three aqueous compartments bounded by lipid bilayers and operates in an aqueous environment. It can receive two chemical signals from the external environment, process them orthogonally, and then produce a distinct output for each signal. It is suitable for both sensing and enzymatic processing of environmental signals with fluorescence and molecular outputs. In the future, such processors could serve as smart drug delivery vehicles or as modules within synthetic tissues to control their behaviour in response to external chemical signals.
\end{abstract}

\section{Introduction}

Lipid-bounded aqueous compartments have applications in drug delivery as well as bottom-up synthetic biology. Single compartment structures are interfaced to an external aqueous environment through a lipid bilayer and may contain sub-compartments ${ }^{1}$. Those devised for drug delivery are designed to release their contents. The release can be passive through biodegradation ${ }^{2}$ or targeted through structural degradation coupled to environmental triggers such as $\mathrm{pH}$, ultrasound or other external signals ${ }^{2-5}$. More sophisticated single compartments exhibit cell-like features. For example, they can employ pore-forming membrane proteins to release contents without structural degradation in response to a trigger ${ }^{1,5}$. They may also receive signals from the environment to activate internal chemical processes such as ATP generation ${ }^{6,7}$, protein expression through transcription and translation ${ }^{7,8}$ or glucose metabolism ${ }^{9}$.

Multi-compartment structures might execute more complex functions, by acting as synthetic tissues ${ }^{10}$. Additional compartments not only can carry out an increased number of individual functions, but also can collectively exhibit emergent properties ${ }^{11,12}$. Much of the work on multi-compartment structures has been conducted in an external oil environment. When two aqueous compartments are placed within a lipid-containing oil, lipid monolayers form around each of them. Hence, when two such compartments are brought together a lipid bilayer forms between them, termed droplet interface bilayer (DIB) ${ }^{13}$. Networks of droplets interconnected by DIBs can be generated manually ${ }^{14,15}$ or by 3Dprinting ${ }^{12,16}$. Within oil, these structures can process external light ${ }^{15,17}$, mechanical ${ }^{18}$ or electrical $^{11}$ stimuli, but they cannot handle input from water-soluble signalling molecules.

To function under physiological conditions, for example as smart drug delivery vehicles, multicompartment structures must operate in an aqueous environment and respond to external chemical signals. Accordingly, multisomes, structures consisting of aqueous compartments inside a lipidcontaining oil drop, have been generated in water ${ }^{19,20}$. One way of forming them is suspending a lipidcontaining oil drop on a Teflon-coated silver wire loop and placing the internal compartments inside 
the oil drop ${ }^{19,21}$. Multisomes have been shown to degrade by design in response to an external $\mathrm{pH}$ or temperature change ${ }^{19}$, and to receive ${ }^{19}$ or send $^{21}$ chemical signals from and to the external environment through pores formed by alpha-hemolysin $(\alpha \mathrm{HL})$ in their lipid bilayers. Multicompartment vesicles, structures composed of compartments interfaced with one another and the external aqueous environment by lipid bilayers without a surrounding oil drop, have been shown to receive a single chemical signal from the environment, through $\alpha \mathrm{HL}$ pores, and activate a single cascade reaction ${ }^{22}$. Therefore, these structures only contained a single signalling pathway and carried out a single task. Natural cells and tissues receive, process and produce several chemical signals, often simultaneously, with little or no cross-talk ${ }^{23-25}$. However, synthetic structures that can simultaneously or independently process multiple external signals to carry out multiple tasks have not been generated.

Here, we produce multi-compartment processors with dedicated signal transmission and processing compartments (Fig. 1a, f). We construct these structures from the bottom up in a modular fashion and show that they can receive and process external chemical signals separately or simultaneously and then produce distinct outputs. The output can be fluorescence, suitable for sensing applications, or the production and release of a molecule, suitable for drug delivery applications or chemical communication. Our processors employ the multisome platform (Fig. 1). When the three aqueous compartments sink inside the oil drop, interface bilayers form between them as well as between each compartment and the external aqueous environment. The signal transmission compartment contains $\alpha \mathrm{HL}$, which forms pores connecting this compartment to the external solution and the two processing compartments. External pores allow the exchange of chemicals between the environment and the signal transmission compartment, whereas the internal pores allow the exchange of chemicals between the signal transmission compartment and the processing compartments. The functionality of the three-compartment processor is reminiscent of a dual-core central processing unit (CPU) with a bus interface and two processing units, where the bus interface handles the flow of information between the rest of the computer and the CPU cores through the front and back side buses ${ }^{26}$ (Fig. 1b). Chemical input signals 1 and/or 2 introduced from the external aqueous environment diffuse through the external and internal pores and reach both processing compartments (Fig. 1c-e). Input signal 1 produces a fluorescence output in the sensing compartment (Fig. 1C). Input signal 2 is converted by the enzymatic processing compartment and the molecular output diffuses through the internal and external pores into the external environment (Fig. 1d). When both input signals are introduced, both outputs are produced simultaneously (Fig. 1e).

\section{Results}

\section{Fast molecular diffusion through pores between compartments}

The most crucial requirement for our chemical signal processors is effective signal transmission. Each chemical input signal must diffuse through two bilayers to reach a processing compartment. After enzymatic processing, the molecular output must then diffuse through two bilayers again to reach the external environment (a total of 4 bilayers), where it becomes diluted by $\sim 20,000$-fold before detection. These factors make fast molecular diffusion essential, which in turn requires efficient insertion of pores into the bilayers.

Diffusion through $\alpha \mathrm{HL}$ pores has been shown with $\mathrm{Ca}^{2+}$ ions $^{1,19,27}$ and a range of small molecules ${ }^{21,28-}$ 30. In these cases, the pores were produced after cell-free expression of $\alpha \mathrm{HL}$ monomers, by using heptamers from $S$. aureus purified by a lengthy procedure, or by using up to $50-60 \mu \mathrm{gL}^{-1}$ of 
commercially sourced monomers from S. aureus. Incomplete diffusion across lipid bilayers was observed in tens of minutes to hours or days. To make our processors feasible, we required much faster diffusion rates.

We expressed recombinant $\alpha \mathrm{HL}$ in $E$. coli and separated the monomers and heptamers by size exclusion chromatography. We studied diffusion of 2-[N-(7-nitrobenz-2-oxa-1,3-diazol-4-yl) amino]-2deoxy-D-glucose (2-NBDG) molecules across droplet interface bilayers within an oil external environment containing 1,2-diphytanoyl-sn-glycero-3-phosphatidylcholine (DPhPC) (Fig. 2a). Mimicking the dimensions of a processor, we formed 250-300 $\mu \mathrm{m}$ diameter signal release compartments containing $1 \mathrm{mM}$ 2-NBDG and 500-650 $\mu \mathrm{m}$ diameter signal transmission compartments containing $200 \mu \mathrm{g} \mathrm{mL}^{-1} \alpha \mathrm{HL}$ monomers (Fig. 2b) or $200 \mu \mathrm{g} \mathrm{mL}^{-1}$ heptamers (Fig. 2c) or no $\alpha \mathrm{HL}$ (Fig. 2d). Using purified $\alpha \mathrm{HL}$ monomers (Fig. 2b), we observed molecular diffusion at unprecedented speeds, with complete equilibration of 2-NBDG molecules within 6 minutes $(n=5)$. We also observed that 2-NBDG diffusion began immediately upon contact of the two compartments and proceeded simultaneously with bilayer formation, as indicated by the increasing contact angle between the compartments ${ }^{16}$ (Supplementary Fig. 1, Supplementary Video 1). With $\alpha \mathrm{HL}$ heptamers ( $n=3$, Fig. $\mathbf{2 c}$ ) or no $\alpha \mathrm{HL}(n=3$, Fig. $\mathbf{2 d}$ ), transfer of 2-NBDG was not visible after 3 days. The high concentration of $\alpha \mathrm{HL}, 200 \mu \mathrm{g} \mathrm{mL}^{-1}$, inside the compartments had no adverse effects on the structures or those shown later in this work.

\section{Exchange of chemical signals with the external environment}

After establishing internal signal transmission between compartments in a lipid-oil external environment, we constructed structures within an aqueous environment. Any chemical output generated by these structures must diffuse through two lipid bilayers, first into the signal transmission compartment, and then into the external aqueous environment. To mimic this process, we built twocompartment structures with a signal release compartment containing 2-NBDG and a signal transmission compartment containing $200 \mu \mathrm{g} \mathrm{mL}^{-1}$ purified $\alpha \mathrm{HL}$ monomers (Fig. 3a) or no $\alpha \mathrm{HL}$. Complete release of $1 \mathrm{mM}$ 2-NBDG through two bilayers to the external environment was observed within 10 minutes ( $n=3$, Fig. 3b, Supplementary Video 2). Without $\alpha \mathrm{HL}$ monomers in the signal transmission compartment, 2-NBDG remained in its original compartment ( $n=3$, Fig. 3c).

Our processor would also need to receive external signals through two bilayers, first into the signal transmission compartment, then into the sensing compartment to produce a fluorescence output (Fig. 3d). To show signal intake and sensing, we built two-compartment structures with a signal transmission compartment containing $200 \mu \mathrm{g} \mathrm{mL}^{-1} \alpha \mathrm{HL}$ monomers, and a sensing compartment containing $20 \mu \mathrm{M}$ dextran-conjugated $\mathrm{Ca}^{2+}$ indicator Rhod-2 ( 11,000 Da). To minimise reagent use, we included a smaller (300-350 $\mu \mathrm{m}$ diameter) sensing compartment, compared to the larger (500$650 \mu \mathrm{m})$ signal transmission compartment. Fluorescence of the Rhod-2 in the sensing compartment increased 3-fold $1 \mathrm{~h}$ after $10 \mathrm{mM} \mathrm{Ca}{ }^{2+}$ addition (Fig. 3e, f) ( $\left.n=4\right)$. When no $\mathrm{Ca}^{2+}$ input signal was added, the fluorescence in the sensing compartment did not increase $(n=3$, Fig. 3f). In fact, in this negative control, the fluorescence decreased as a result of excess chelator in the external solution, initially added to prevent the binding of trace metal ions to Rhod-2, diffusing into the sensing compartment (see Supplementary Note). 


\section{Input-activated enzymatic reaction with fluorescence output}

The next step was to couple signal intake with activation of an enzymatic process. We chose a restriction endonuclease, EcoRl, which requires $\mathrm{Mg}^{2+}$ as a co-factor ${ }^{31}$, and had not been encapsulated in synthetic biological systems before. As a substrate, we designed a molecular beacon based on a previously published sequence ${ }^{32}$ : a DNA hairpin with a fluorophore attached on the $5^{\prime}$ end and a quencher on the $3^{\prime}$ end, containing an EcoRI cleavage site 4 and 8 bases away from the $5^{\prime}$ and $3^{\prime}$ ends, respectively ${ }^{32}$. To produce high quenching efficiency ${ }^{33}$, we used the fluorophore Cyanine 5 and the quencher BHQ- $3^{34}$. Upon cleavage at the EcoRI site, the fluorophore/quencher pair separates due to DNA denaturation, resulting in a fluorescence signal (Fig. 4a).

We built two-compartment processors with a signal transmission compartment containing $\alpha \mathrm{HL}$ monomers, and an enzymatic processing compartment containing $400 \mathrm{U} \mathrm{mL}^{-1} \mathrm{EcoRI}$ and $400 \mathrm{nM}$ DNA substrate. To minimise reagent use, we included 300-350 $\mu \mathrm{m}$ diameter enzymatic processing compartments and 500-650 $\mu \mathrm{m}$ diameter signal transmission compartments containing $200 \mu \mathrm{g} \mathrm{mL}-1$ $\alpha \mathrm{HL}$ monomers. $\mathrm{Mg}^{2+}$ input signal added to the external aqueous environment diffused through the signal transmission compartment into the processing compartment where it induced the cleavage reaction and the fluorescence output (Fig. 4b). Fluorescence in the EcoRI compartment increased 19fold $2 \mathrm{~h}$ after $10 \mathrm{mM} \mathrm{Mg}{ }^{2+}$ addition (Fig. $4 \mathrm{c}$, d) and incubation at $37{ }^{\circ} \mathrm{C}(n=6)$. When no $\mathrm{Mg}^{2+}$ was added, the fluorescence in the EcoRI compartment remained constant $(n=6$, Fig. 4d). Notably, we obtained stable structures despite the use of $100 \mathrm{mg} \mathrm{mL}^{-1}$ bovine serum albumin (BSA) in the enzymatic processing compartment. For these structures, we initially used $200 \mu \mathrm{g} \mathrm{mL}^{-1} \alpha \mathrm{HL}$ monomers in the signal transmission compartment and did not observe an increase in fluorescence in the EcoRI compartment after the addition of external $\mathrm{Mg}^{2+}$. We made new structures with a reduced $\alpha \mathrm{HL}$ concentration (see Methods) and were then able to detect the fluorescence signal (Fig. 4c, d). This indicated that the fluorescent product was diffusing out of the reaction compartment through the pores, which we confirmed by fluorescence measurements on the signal transmission compartment (Supplementary Fig. 2).

\section{Input-activated enzymatic reaction with molecular output}

Having shown ionic signal intake and enzymatic activation in two-compartment processors, we next aimed to demonstrate molecular signal intake, enzymatic turnover, and output of the product molecule into the external environment. We built two-compartment processors with a signal transmission compartment containing $200 \mu \mathrm{g} \mathrm{mL}^{-1} \alpha \mathrm{HL}$ monomers, and an enzymatic processing compartment containing $700 \mu \mathrm{g} \mathrm{mL}^{-1}\left(30 \mathrm{U} \mathrm{mL}^{-1}\right) \beta$-galactosidase, which hydrolyses lactose into glucose and galactose (Fig. 5a). The lactose input signal, added to the external aqueous environment, diffused through two bilayers, first to the signal transmission compartment and then to the processing compartment where it was hydrolysed. The product glucose was then released back through the same two bilayers into the external environment as a molecular output (Fig. 5b). In our set up, the external environment was $800 \mu \mathrm{L}$ in volume. As the product glucose would be diluted upon release to the external environment, we included larger enzymatic processing compartments $(400-470 \mu \mathrm{m}$ in diameter, $\sim 40 \mathrm{~nL}$ in volume) than those we previously used for fluorescence output. Using these larger $\beta$-galactosidase compartments, the product glucose was still diluted by $\sim 20,000$-fold upon release. We used signal transmission compartments of the same size as previously used. After $40 \mathrm{mM}$ lactose addition and incubation at $37^{\circ} \mathrm{C}$ for $6 \mathrm{~h}$, glucose was detected in the external environment by using a commercial assay ( $n=6$, Fig. 5c). When no lactose was added, no glucose was detected ( $n=6$, Fig. 5c). In processors incubated with lactose, the $\beta$-galactosidase compartment shrank (Fig. $\mathbf{5 d}$ ). We attribute 
this observation to the increased osmotic pressure of the external aqueous environment. On the other hand, the signal transmission compartment, interfaced directly with the external environment through $\alpha \mathrm{HL}$ pores, was better able to take in solutes and reach osmotic equilibrium. The processors remained intact despite the volume changes.

\section{Orthogonal processing of two input signals}

At this stage, we had all the parts required to build a processor that would independently and simultaneously process two external signals. Combining a signal transmission compartment containing $200 \mu \mathrm{g} \mathrm{mL}^{-1} \alpha \mathrm{HL}$ monomers, a sensing compartment containing $20 \mu \mathrm{M}$ dextran-conjugated Rhod-2, and an enzymatic processing compartment containing $700 \mu \mathrm{g} \mathrm{m}^{-1} \beta$-galactosidase, we constructed three-compartment processors (Fig. 6a). We tested these processors with all four possible input signal combinations: no in put signals, only $\mathrm{Ca}^{2+}$, only lactose, and both $\mathrm{Ca}^{2+}$ and lactose (Fig. $\mathbf{6 b}$ ). When no input signals were added, fluorescence in the Rhod-2 compartment decreased and no glucose was detected in the external environment, after $3 \mathrm{~h}$ at $37^{\circ} \mathrm{C}(n=4)$. Addition of only the $\mathrm{Ca}^{2+}$ input signal led to a fluorescence output in the Rhod-2 compartment and no glucose was detected in the external environment $(n=5)$. When only the lactose input signal was added, the fluorescence of the Rhod-2 compartment decreased, and glucose was detected in the external environment $(n=4)$. When both input signals were added, fluorescence in the Rhod-2 compartment increased (Fig. 6b, c) and glucose was detected in the external environment ( $n=5$, Fig. $6 \mathbf{b})$. These results demonstrate the orthogonal processing of two chemical inputs within a lipid-bound multicompartment structure.

\section{Simultaneous enzymatic processing of two input signals}

To demonstrate simultaneous enzymatic processing, we constructed processors with a signal transmission compartment containing $200 \mu \mathrm{g} \mathrm{mL}-1$ $\alpha \mathrm{HL}$ monomers and two enzymatic processing compartments: one containing $400 \mathrm{U} \mathrm{mL}^{-1} \mathrm{EcoRI}$ with $400 \mathrm{nM}$ DNA substrate and one containing 700 $\mu \mathrm{g} \mathrm{mL} \mathrm{m}^{-1} \beta$-galactosidase (Fig. 7a). We had to find a $\mathrm{pH}$ value that would allow both reactions to proceed, and selected pH 6.5 as a compromise (Supplementary Fig. 3, 4). The addition of both input signals, $10 \mathrm{mM} \mathrm{Mg}^{2+}$ and $40 \mathrm{mM}$ lactose, followed by incubation at $37^{\circ} \mathrm{C}$ for $3 \mathrm{~h}$ generated increased fluorescence in the EcoRI compartment (Fig. 7b, c) and glucose in the external environment (Fig. 7b) simultaneously $(n=3)$, despite the suboptimal reaction conditions.

\section{Discussion}

In summary, we have constructed processors from lipid bilayer-bounded compartments from the bottom up, in a modular fashion. By using purified recombinant $\alpha \mathrm{HL}$ monomers, we achieved fast diffusion of ionic and molecular signals across as many as 4 lipid bilayers. We first demonstrated the release and intake of chemical signals in two-compartment structures. We then encapsulated enzymatic processes within them and with an ionic input signal, we activated DNA cleavage. We also demonstrated the enzymatic hydrolysis of a molecular input signal and release of the product into the external environment as a molecular output. By combining different components in a modular fashion, we built three-compartment processors that receive and process two different chemical signals in an orthogonal manner, producing two distinct outputs: fluorescence and molecule release. We also showed simultaneous activation of different enzymes in two separate compartments of a three-compartment processor. This work represents the first bottom-up synthetic biological system 
with independent and simultaneous processing of more than one signal, and serves as a steppingstone in the development of multi-compartment systems with complex signal processing capabilities. As a result of the use of the recombinant $\alpha \mathrm{HL}$ monomers introduced in this work, engineered $\alpha \mathrm{HL}$ pores might be used at high concentrations to modulate signal transmission using small molecules ${ }^{21,35,36}$, light ${ }^{37}$ or other stimuli ${ }^{38,39}$, adding further complexity to the tasks performed by future structures.

Our processors are modular, robust and versatile. Lipid-bounded compartments in an external aqueous environment often suffer from structural instability ${ }^{21,27}$, which can be addressed by balancing osmotic pressures during construction ${ }^{21,29}$ but limiting the applicability of these structures in dynamic environments. Our processors, functionalised with fast signal processing capabilities involving enzymatic reactions, can withstand changing osmotic pressures. They also incorporate high concentrations of enzymes and membrane proteins and are stable at $37^{\circ} \mathrm{C}$.

Due to their modularity and robustness, the processors might be adapted for a variety of applications. To simultaneously process complex sets of input signals, several processing units could be connected to a large signal transmission compartment (Supplementary Fig. 5, Supplementary Video 3). The platform could be used to build sensors and micro-reactors. For example, the encapsulation of suitable reporters would allow parallel processing in medical diagnostics, water quality analysis, or the sensing of bacteria. Micro-reactors could be built by combining compartments that encapsulate multiple independent reactions, cooperative reactions forming a cascade, or both. The multi-compartment processors might also be incorporated into drug delivery systems or synthetic tissues to enable complex communication with their environment through parallel signal processing. For example, the processors could be engineered to monitor multiple biomarkers and integrate outputs for sophisticated drug delivery. In the future, these processors could also be used to handle signals between interfaced synthetic and living tissues, coordinating them to act as functional hybrid systems. 
bioRxiv preprint doi: https://doi.org/10.1101/2021.05.05.442835; this version posted May 5, 2021. The copyright holder for this preprint (which was not certified by peer review) is the author/funder, who has granted bioRxiv a license to display the preprint in perpetuity. It is made available under aCC-BY-NC-ND 4.0 International license.

\section{Figures}

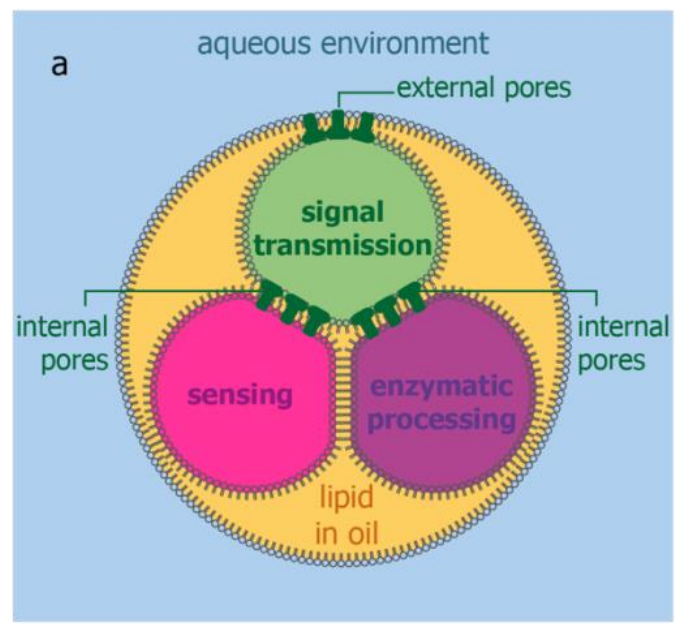

C
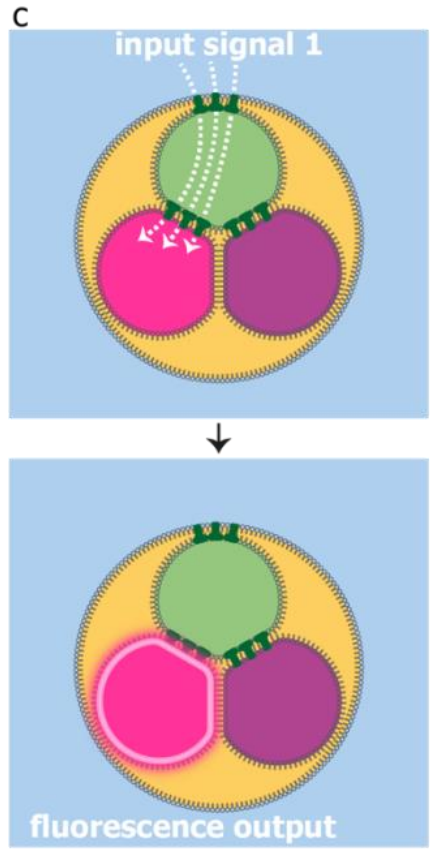

d
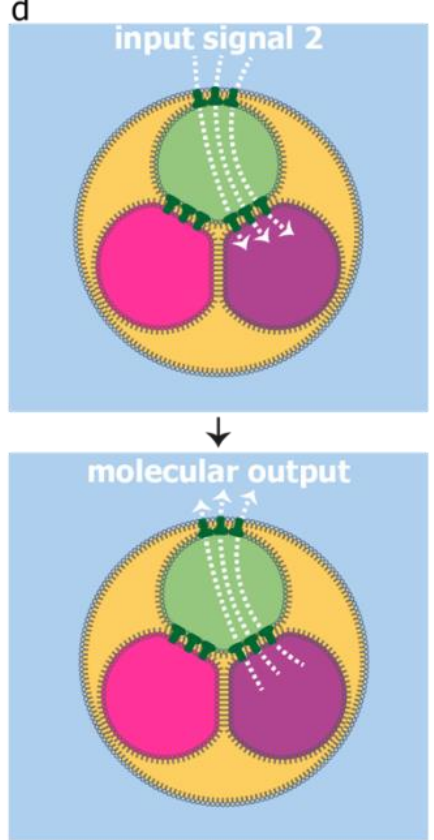

b

information flow

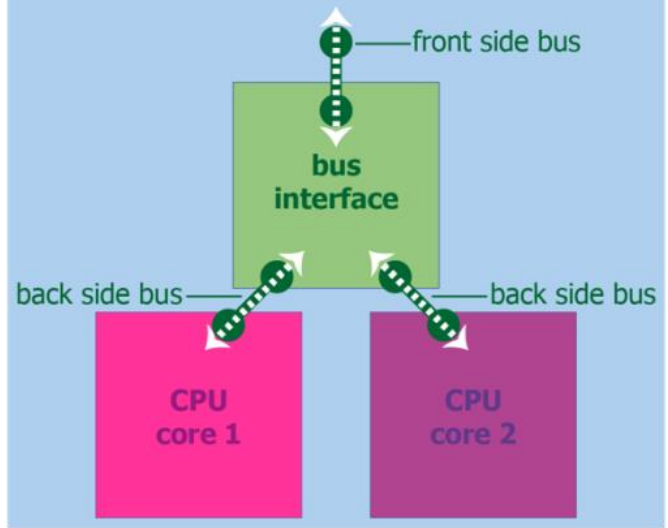

e

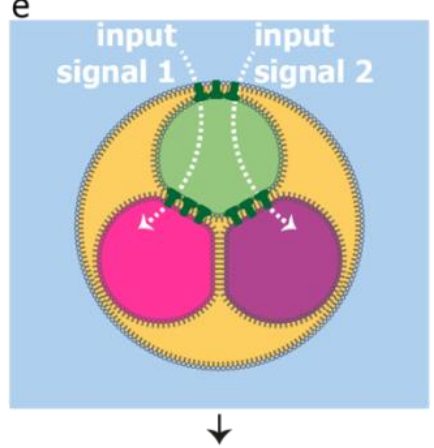

molecular output

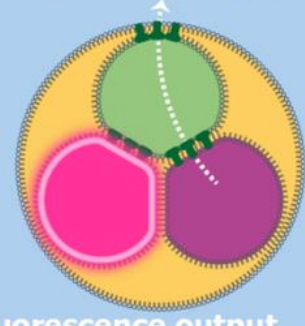

fluorescence output

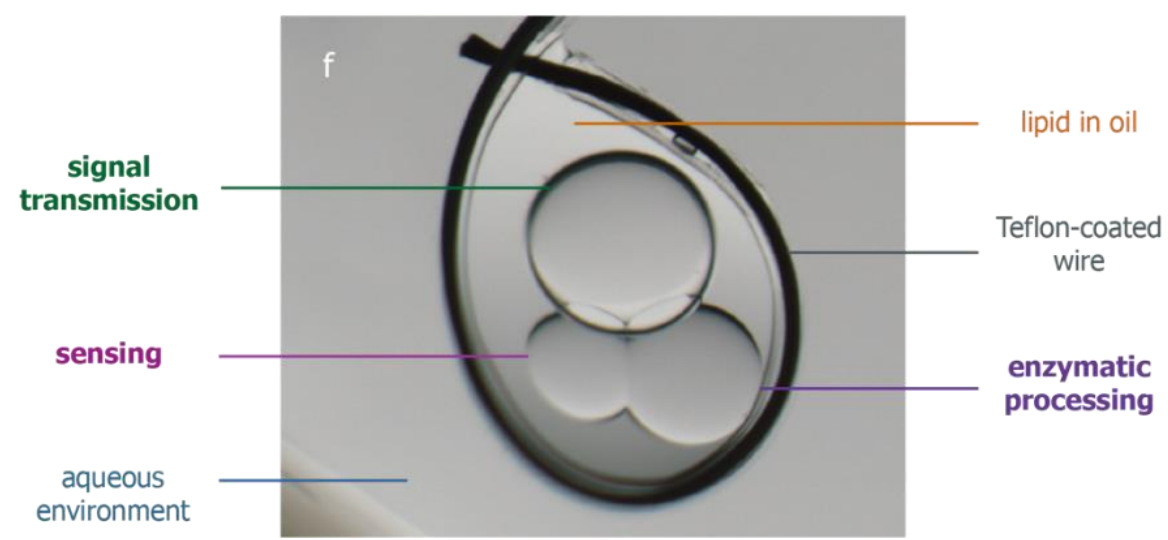

Fig. 1: Three-compartment processor with sensing and enzymatic processing compartments. a Three-compartment processor for chemical signals containing sensing and enzymatic processing 
compartments. A signal transmission compartment enables communication between the processing compartments and the external environment. b Diagram of a dual-core CPU, analogous to the threecompartment processor. c Sensing in a three-compartment processor by intake of input signal 1 and production of a fluorescence output in the sensing compartment. $\mathbf{d}$ Enzymatic processing in a threecompartment processor by intake of input signal 2 and production of a molecular output and its release into the external environment by the enzymatic processing compartment. e Simultaneous sensing and enzymatic processing in a three-compartment processor by intake of both input signals and production of two distinct outputs. $\mathbf{f}$ Top view of a three-compartment processor contained in an oil drop suspended on a Teflon-coated silver wire loop within an aqueous environment. Wire diameter $=76 \mu \mathrm{m}$. 
a

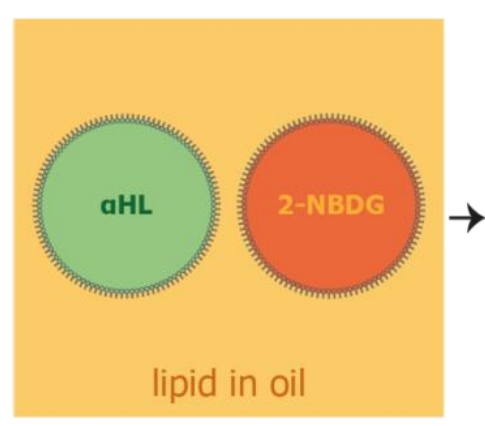

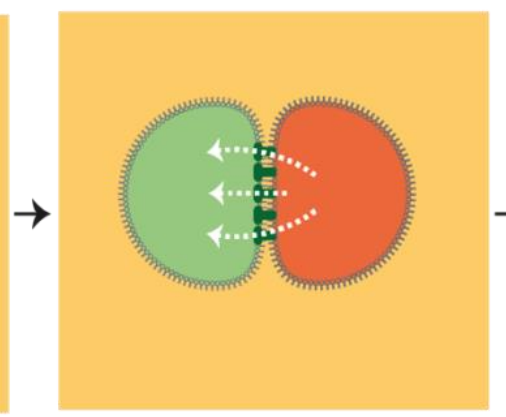

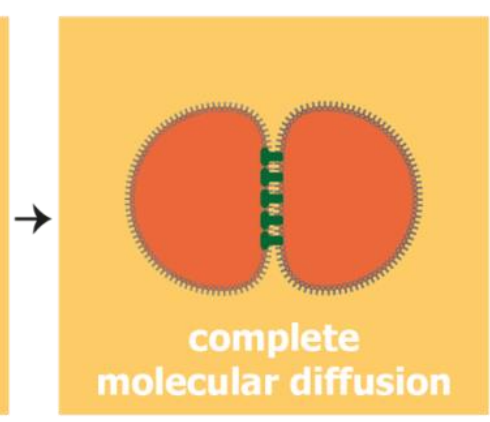

purified aHL monomers heptamerised in situ

b

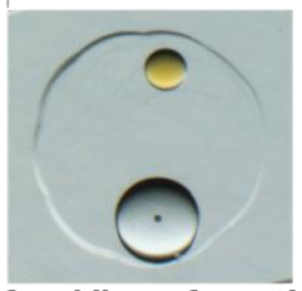

before bilayer formation

purified aHL heptamers

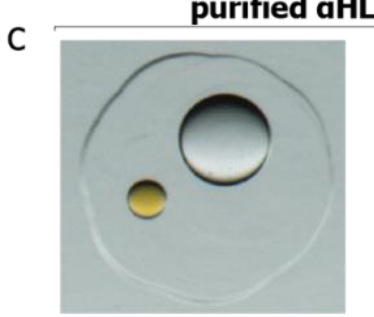

before bilayer formation

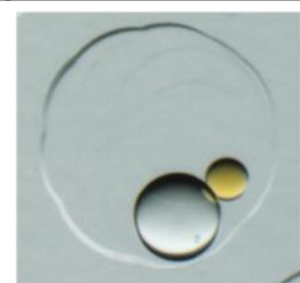

$\mathbf{t}=\mathbf{0} \min$

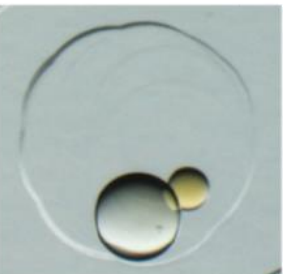

$\mathbf{t}=\mathbf{3} \min$

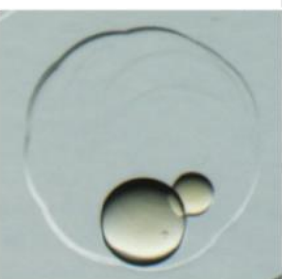

$\mathbf{t}=\mathbf{6} \min$ no aHL d

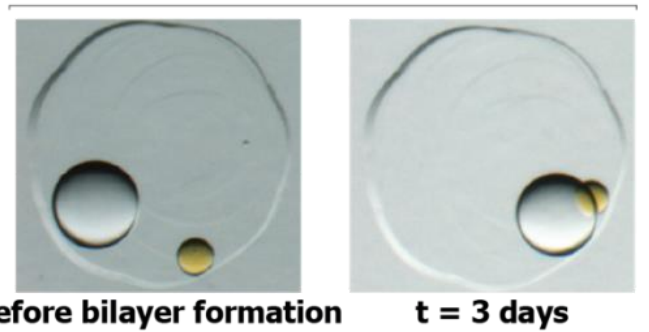

Fig. 2: Fast diffusion of molecular signals across lipid bilayers. a Bilayer formation between a signal transmission and a signal release compartment within a lipid-oil external environment, leading to diffusion of 2-NBDG molecules through $\alpha$-hemolysin ( $\alpha \mathrm{HL}$ ) pores. b-d Bright-field microscopy images of molecular diffusion from compartments containing 2-NBDG into signal transmission compartments containing purified $\alpha H L$ monomers (b), purified $\alpha H L$ heptamers (c), and no $\alpha H L$ (d). 
a
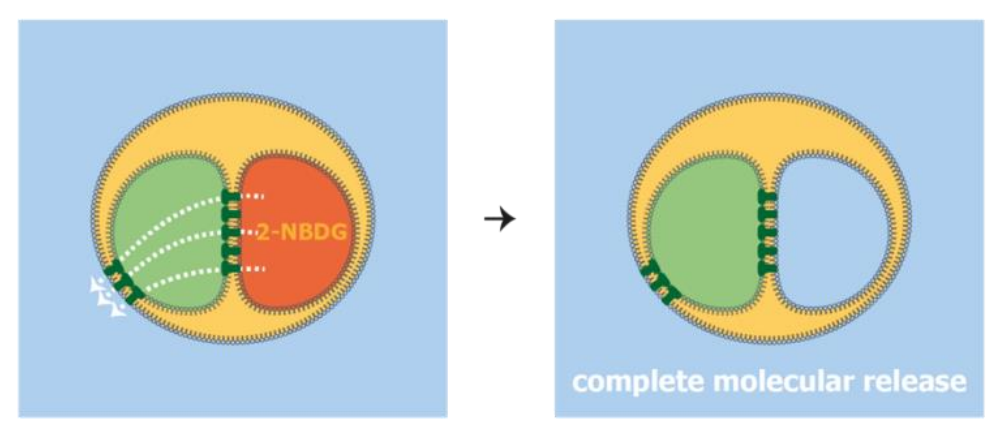

purified aHL monomers heptamerised in situ

b
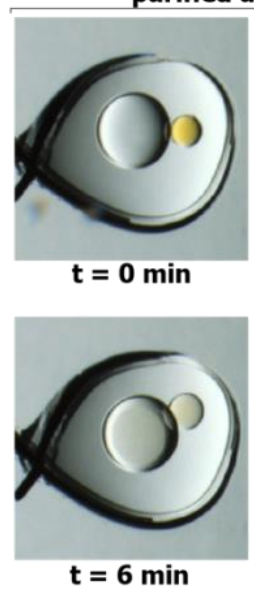

d
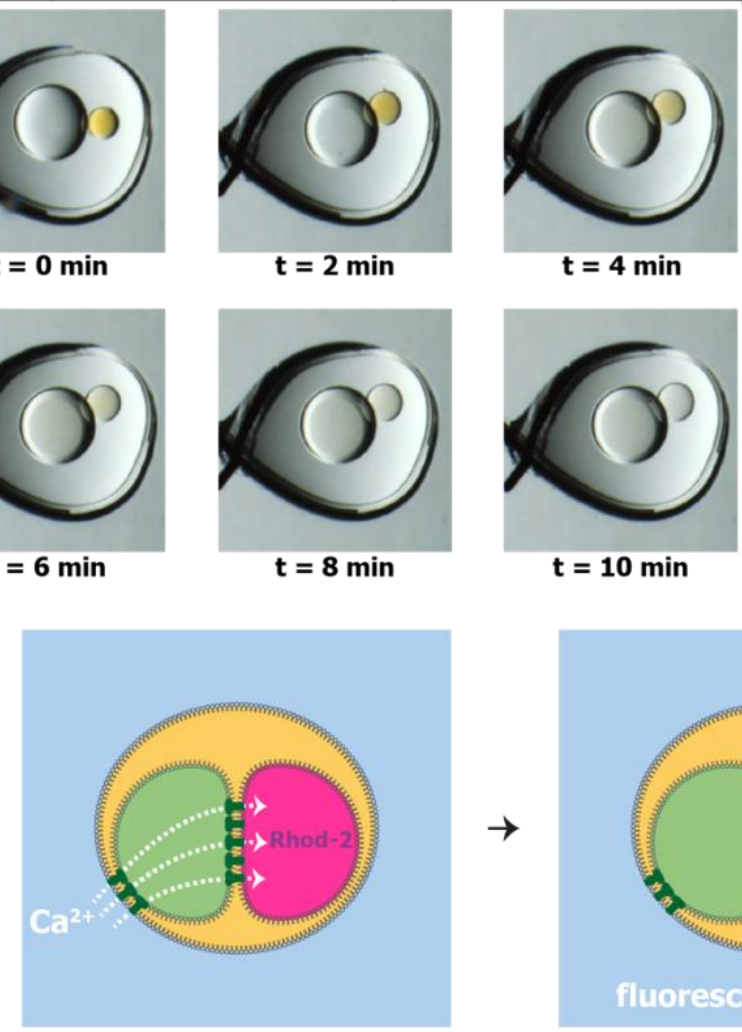

$\mathbf{t}=\mathbf{2} \mathbf{m i n}$

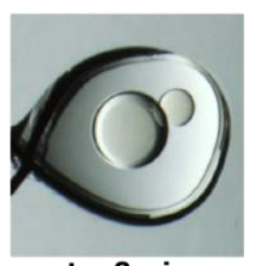

$\mathbf{t}=\mathbf{8} \mathrm{min}$

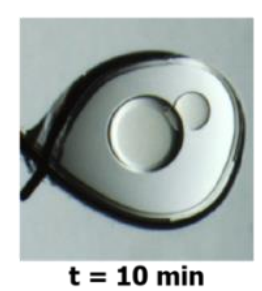

c
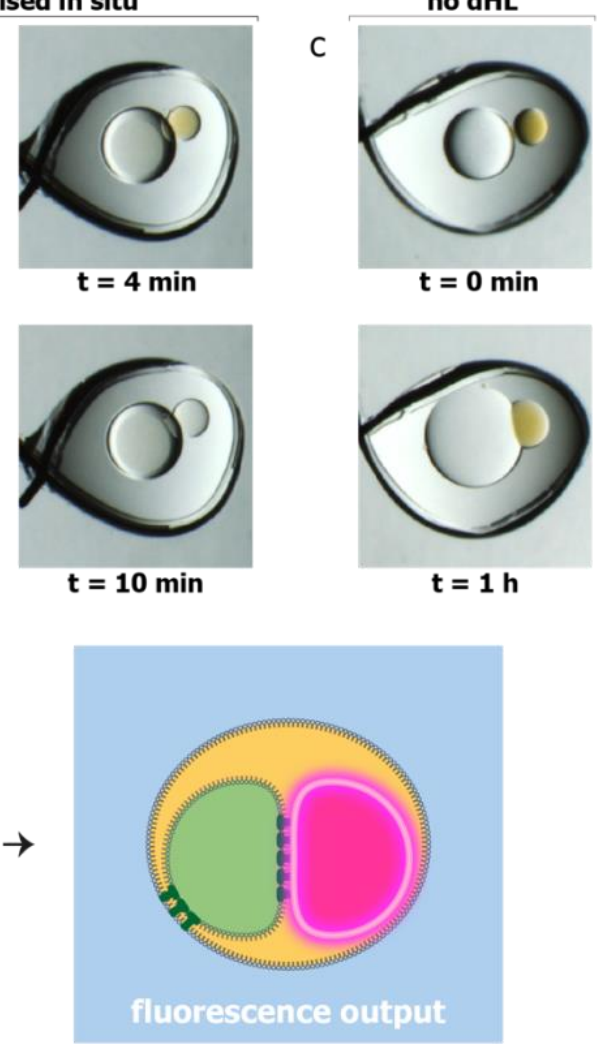

e

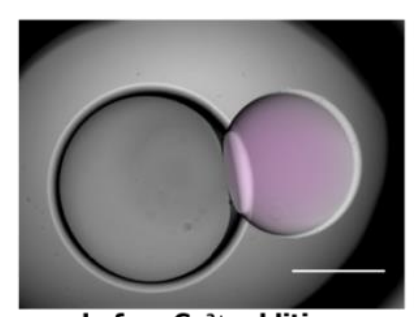

before $\mathrm{Ca}^{2+}$ addition

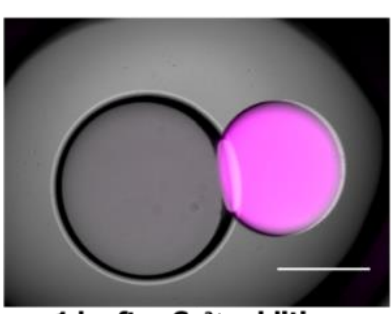

$1 \mathrm{~h}$ after $\mathrm{Ca}^{2+}$ addition

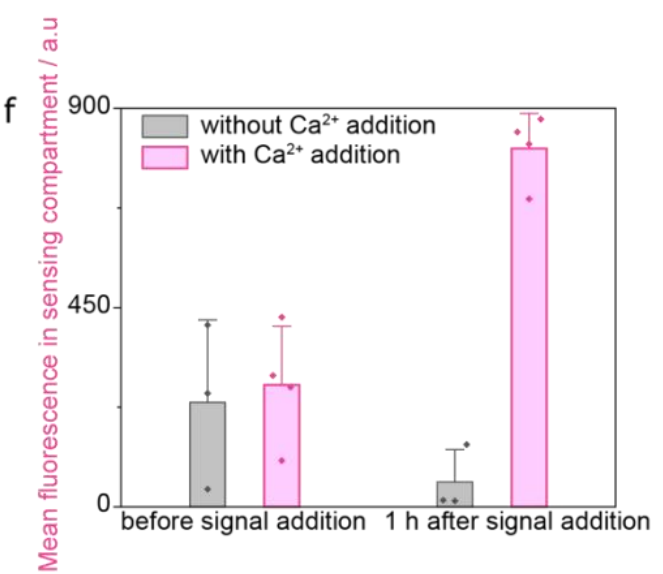

Fig. 3: Output and intake of chemical signals in an external aqueous environment. a Output of chemical signal 2-NBDG through a signal transmission compartment, leading to its release into the external aqueous environment. b-c Bright-field microscopy images of 2-NBDG release into the external aqueous environment through signal transmission compartments with purified $\alpha \mathrm{HL}$ 
monomers (b) and without $\alpha \mathrm{HL}$ (c). Wire diameter $=76 \mu \mathrm{m}$. $\mathbf{d}$ Intake of chemical signal $\mathrm{Ca}^{2+}$ through the signal transmission compartment, leading to a fluorescence output in the sensing compartment, which contains dextran-conjugated Rhod-2. e Composite bright-field and epifluorescence images of signal transmission from the external environment into the sensing compartment before and $1 \mathrm{~h}$ after $\mathrm{Ca}^{2+}$ addition to the external aqueous environment. Scale bars $=300 \mu \mathrm{m}$. $\mathrm{f}$ Mean fluorescence values of the sensing compartment before and $1 \mathrm{~h}$ after $\mathrm{Ca}^{2+}$ addition without $(n=3)$ and with $(n=4) \mathrm{Ca}^{2+}$ addition. Error bars represent the standard deviation. 
a

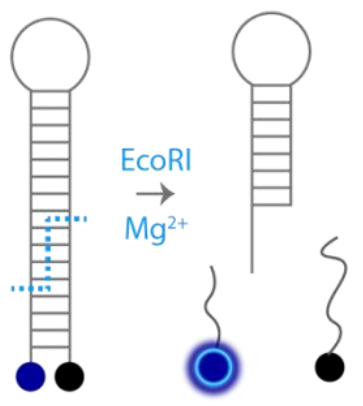

b

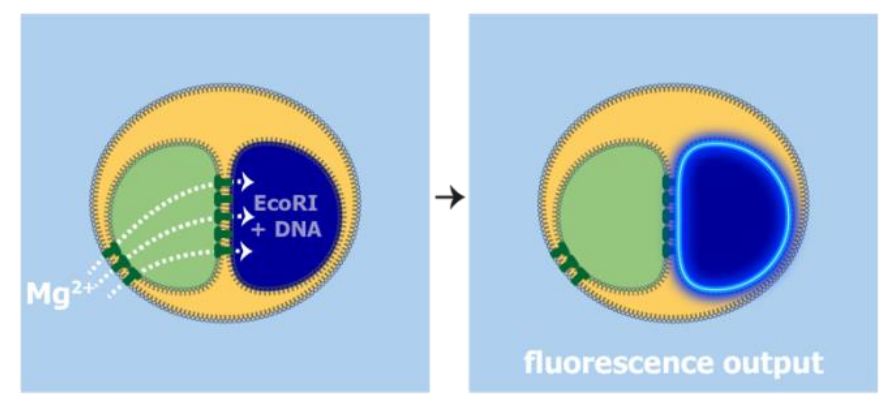

C

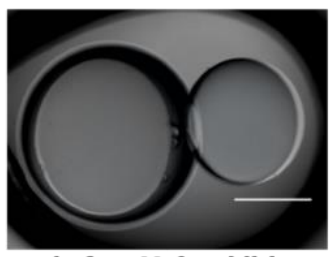

before $\mathrm{Mg}^{2+}$ addition

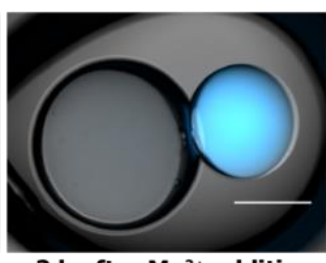

$\mathbf{2} \mathrm{h}$ after $\mathrm{Mg}^{2+}$ addition

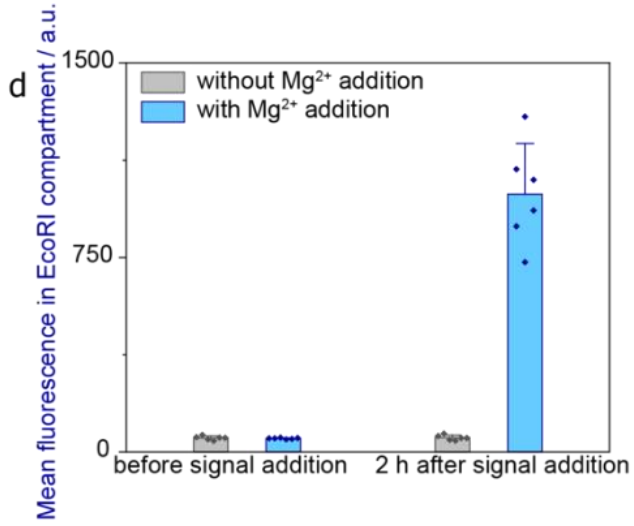

Fig. 4: Enzymatic processing by EcoRI in two-compartment processors: signal intake, signal processing and fluorescence output. a Design of a $\mathrm{Mg}^{2+}$-dependent enzymatic process with a fluorescence output. Upon addition of the input signal, a molecular beacon is cleaved by the endonuclease EcoRI, leading to fluorophore/quencher pair separation and a fluorescence output signal. $\mathbf{b}$ Intake of ionic signal $\mathrm{Mg}^{2+}$ from the external aqueous environment into a two-compartment processor, and activation of enzymatic processing by EcoRI to produce a fluorescence output. c Composite bright-field and epifluorescence images of a two-compartment processor containing EcoRI and the DNA substrate before and after $\mathrm{Mg}^{2+}$ addition into the external aqueous environment and 2 $\mathrm{h}$ at $37{ }^{\circ} \mathrm{C}$. Scale bars $=300 \mu \mathrm{m}$. $\mathbf{d}$ Mean fluorescence values of the EcoRI-containing compartment before and $2 \mathrm{~h}$ after $\mathrm{Mg}^{2+}$ addition and incubation at $37{ }^{\circ} \mathrm{C}$ without $(n=6)$ and with $(n=6) \mathrm{Mg}^{2+}$ addition. Error bars represent the standard deviation. 


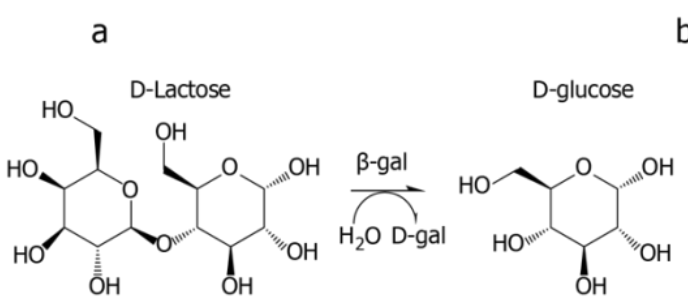

C

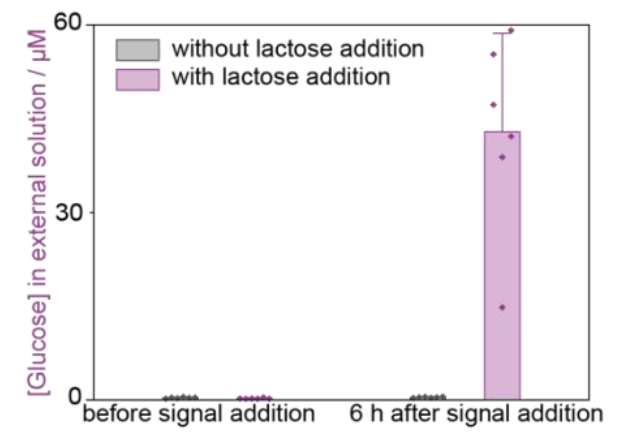

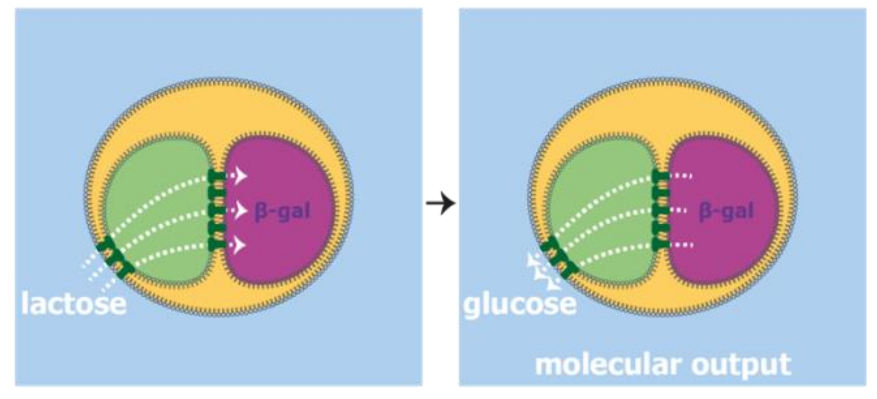

$\mathrm{d}$

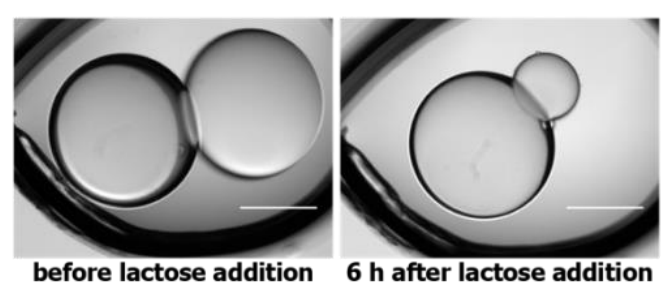

Fig. 5: Enzymatic processing by $\beta$-galactosidase in two-compartment processors: signal intake, signal processing, small molecule production and release. a Hydrolysis of D-lactose by $\beta$-galactosidase ( $\beta$ gal) produces $D$-galactose ( $D$-gal) and $D$-glucose. $\mathbf{b}$ Intake of the molecular input signal lactose from the external environment into a two-compartment processor, its enzymatic processing and release of the product glucose into the external environment. c Concentration of glucose in the external aqueous environment before and $6 \mathrm{~h}$ after lactose addition and incubation at $37^{\circ} \mathrm{C}$, without $(n=6)$ and with $(n$ = 6) lactose addition. Error bars represent the standard deviation. $\mathbf{d}$ Bright-field microscopy images of a two-compartment processor containing $\beta$-galactosidase before and after lactose addition and processing. Scale bars $=300 \mu \mathrm{m}$. 

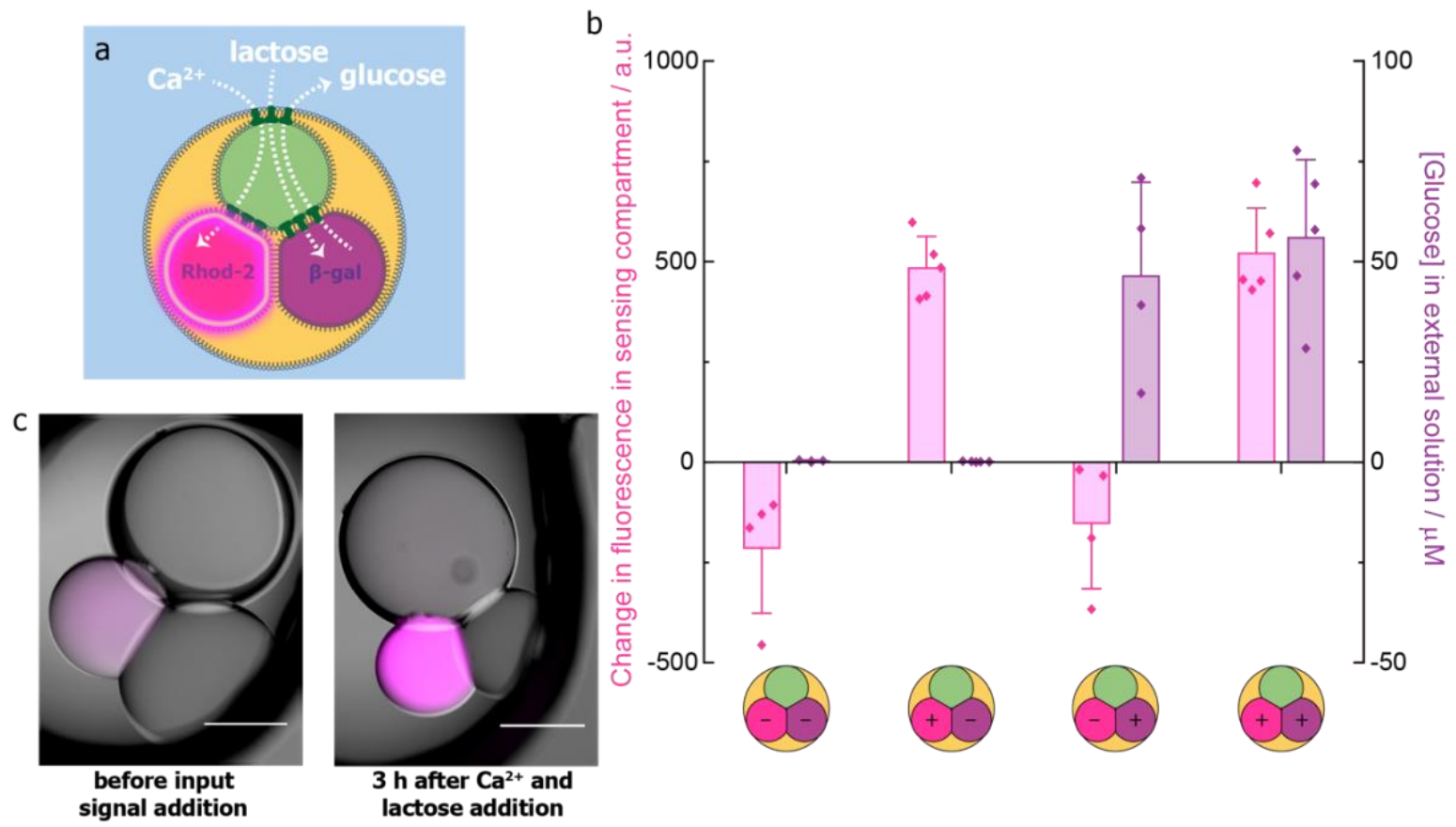

Fig. 6: Independent and simultaneous sensing and enzymatic processing in three-compartment processors. a Three-compartment processor containing signal transmission, sensing and enzymatic processing compartments. The intake of $\mathrm{Ca}^{2+}$ leads to a fluorescence output in the sensing compartment containing Rhod-2, whereas the intake of lactose leads to the production of glucose by $\beta$-galactosidase and its release into the external environment. $\mathbf{b}$ Changes in the mean fluorescence of Rhod-2 compartments and the mean concentration of glucose detected in the external solution after $3 \mathrm{~h}$ at $37{ }^{\circ} \mathrm{C}$ for three-compartment processors with no input signals $(n=4)$ and with an input of $\mathrm{Ca}^{2+}$ only $(n=5)$, lactose only $(n=4)$, and both $\mathrm{Ca}^{2+}$ and lactose $(n=5)$. Error bars represent the standard deviation. c Composite bright-field and epifluorescence images of a three-compartment processor with a sensing compartment containing Rhod- 2 and an enzymatic processing compartment containing $\beta$-galactosidase before and after simultaneous addition of $\mathrm{Ca}^{2+}$ and lactose input signals and $3 \mathrm{~h}$ at 37 ${ }^{\circ} \mathrm{C}$. Scale bars $=300 \mu \mathrm{m}$. 

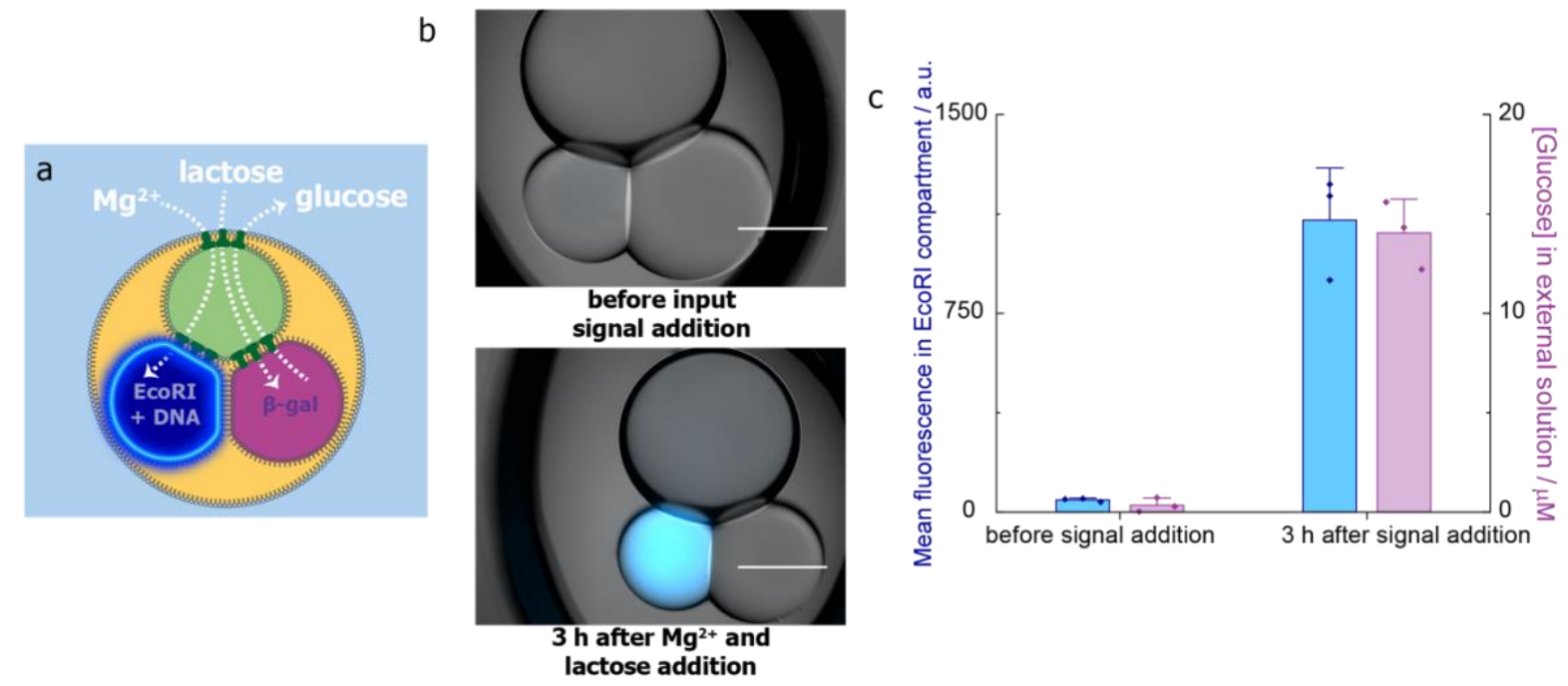

Fig. 7: Simultaneous enzymatic processing in three compartment processors. a Three-compartment processor for simultaneous enzymatic processing by EcoRI and $\beta$-galactosidase activated by input signals $\mathrm{Mg}^{2+}$ and lactose, respectively. $\mathbf{b}$ Composite bright-field and epifluorescence images of a threecompartment processor with EcoRI and $\beta$-galactosidase processing compartments before and after the simultaneous addition of $\mathrm{Mg}^{2+}$ and lactose and $3 \mathrm{~h}$ incubation at $37^{\circ} \mathrm{C}$. Scale bars $=300 \mu \mathrm{m}$. c Mean fluorescence values in EcoRl-containing compartment and the mean concentration of glucose detected in the external solution before and after the simultaneous addition of $\mathrm{Mg}^{2+}$ and lactose and $3 \mathrm{~h}$ at $37^{\circ} \mathrm{C}(n=3)$. 


\section{Methods}

\section{$\alpha H L$ expression and purification}

BL21(DE3)pLysS E. coli cells (Agilent) were transformed with $2 \mu \mathrm{g} \alpha \mathrm{HL}-\mathrm{D} 8 \mathrm{H} 6$ plasmid ${ }^{40}$ without heat shock and incubated on LB-agar plates containing $25 \mathrm{~g} \mathrm{~L}^{-1}$ lysogeny broth (LB) and $15 \mathrm{~g} \mathrm{~L}^{-1}$ agar with antibiotics ( $50 \mu \mathrm{g} \mathrm{mL} \mathrm{L}^{-1}$ carbenicillin disodium and $34 \mu \mathrm{g} \mathrm{mL} \mathrm{L}^{-1}$ chloramphenicol) at $37^{\circ} \mathrm{C}$ for $16 \mathrm{~h}$. Single colonies were picked and inoculated into $15 \mathrm{~g} \mathrm{~L}^{-1} \mathrm{LB}$ with antibiotics at $37^{\circ} \mathrm{C}$ with shaking at $250 \mathrm{rpm}$ until $\mathrm{OD} \approx 0.7$. The cultures were then induced with $1 \mathrm{mM}$ isopropyl $\beta$-d-1-thiogalactopyranoside (IPTG) and incubated at $18{ }^{\circ} \mathrm{C}$ with shaking at $250 \mathrm{rpm}$ for $16 \mathrm{~h}$. Between this point and Fast Protein Liquid Chromatography (FPLC) purification, all steps were carried out at $4{ }^{\circ} \mathrm{C}$. The cells were pelleted and lysed in $50 \mathrm{mM}$ Tris- $\mathrm{HCl}, \mathrm{pH} 8.0,0.5 \mathrm{M} \mathrm{NaCl}, 10 \mathrm{mM}$ imidazole and $0.1 \%$ Triton X-100 followed by the addition of ice-cold $\mathrm{MgCl}_{2}$ (final concentration, $5 \mathrm{mM}$ ), hen egg white lysozyme (final concentration, $1 \mathrm{mg} \mathrm{mL}^{-1}$ ) and 250 units benzonase.

The resulting lysate was sonicated using an ultrasonic probe with $30 \mathrm{~s}$ pulses and $30 \mathrm{~s}$ intervals for 3 min followed by centrifugation to separate the supernatant and cell debris. The supernatant was loaded onto a column pre-loaded with $2 \mathrm{~mL}$ Ni-NTA resin (HisPur) and placed on a rotator disk for $1 \mathrm{~h}$. The column was then washed twice with $15 \mathrm{~mL}$ of $50 \mathrm{mM}$ Tris- $\mathrm{HCl} \mathrm{pH} \mathrm{8.0,0.5} \mathrm{M} \mathrm{NaCl}, 10 \mathrm{mM}$ imidazole and $0.1 \%$ Triton X-100. Proteins were eluted in $5 \times 1 \mathrm{~mL}$ batches with $50 \mathrm{mM}$ Tris- $\mathrm{HCl} \mathrm{pH} \mathrm{8.0,0.5} \mathrm{M}$ $\mathrm{NaCl}, 250 \mathrm{mM}$ imidazole and $0.1 \%$ Triton $\mathrm{X}-100$ and stored at $-80^{\circ} \mathrm{C}$ until FPLC purification.

To separate monomers and heptamers and exchange the buffer, $500 \mu \mathrm{L}$ of an elution with high protein concentration, as judged by SDS-PAGE electrophoresis, was loaded at room temperature onto a Superdex 75 100/300 GL (GE Healthcare) gel filtration column which was equilibrated and run in 10 $\mathrm{mM}$ Tris- $\mathrm{HCl} \mathrm{pH} 8.0,200 \mathrm{mM} \mathrm{NaCl}$ at a flow rate of $0.5 \mathrm{~mL} \mathrm{~min} \mathrm{~m}^{-1}$ and eluted as $0.5 \mathrm{~mL}$ volume per fraction. Monomeric and heptameric $\alpha \mathrm{HL}$ were detected by ultraviolet absorption at 254 and $280 \mathrm{~nm}$, and by SDS-PAGE electrophoresis. Protein concentrations were measured using a Nanodrop. The fractions with highest concentrations $\left(200-400 \mu \mathrm{g} \mathrm{mL}^{-1}\right)$ were stored as 5-10 $\mu \mathrm{L}$ aliquots in Protein LoBind tubes (Eppendorf) at $-80^{\circ} \mathrm{C}$.

\section{Compositions of solutions}

1,2-Diphytanoyl-sn-glycero-3-phosphocholine (DPhPC, Avanti Polar Lipids) was stored as powder at $80^{\circ} \mathrm{C}$. Hexadecane (Merck) and silicone oil AR20 (Wacker) were filtered before use through $0.22 \mu \mathrm{m}$ polyethersulfone filters (Corning) under vacuum. Lipid-oil solutions were prepared by dissolving the desired amount of lipid in chloroform in isopropanol-cleaned glass vials and evaporating the solvent under a slow stream of nitrogen gas while manually rotating. The films were dried under vacuum overnight and stored under argon in Teflon-capped glass vials (Supelco). For use, a film was dissolved by sonication for $45 \mathrm{~min}$ in 65:35 v:v silicone oil:hexadecane to give $2 \mathrm{mM}$ DPhPC (5 mM for Supplementary Fig. 1).

Rhod-2 dextran conjugate ( $\sim 11,000 \mathrm{Da})$ was from AAT Bioquest. 2-(N-(7-Nitrobenz-2-oxa-1,3-diazol4-yl)amino)-2-deoxyglucose (2-NBDG), the tetrapotassium salt of BAPTA and the Amplex Red Glucose/Glucose Oxidase Assay Kit were from Invitrogen. EcoRI-HF was from New England Biolabs. All other reagents used in aqueous solutions were purchased from Merck. $\beta$-galactosidase from $A$. oryzae was purified with a PD-10 Desalting Column (GE Healthcare). The custom-made DNA substrate was purchased from ATDBio. It was designed based on a sequence described previously ${ }^{32}$, but with the fluorophore Cyanine 5 on the $5^{\prime}$ end and the quencher Black Hole Quencher (BHQ-3) on the $3^{\prime}$ end. 
An individual aliquot of $\alpha \mathrm{HL}$ was thawed on ice for each experiment and diluted with $10 \mathrm{mM} \mathrm{Tris}-\mathrm{HCl}$ $\mathrm{pH}$ 8.0, $200 \mathrm{mM} \mathrm{NaCl}$ to give $200 \mu \mathrm{g} \mathrm{mL} \mathrm{m}^{-1} \alpha \mathrm{HL}$. For processors involving a compartment containing EcoRI and DNA, the $\alpha \mathrm{HL}$ was diluted further to a concentration at which the equilibration of 2-NBDG across a bilayer (Fig. 2) took 20-30 min.

All other compartments and external aqueous environments contained $50 \mathrm{mM} \mathrm{MES}, 100 \mathrm{mM} \mathrm{NaCl}$ at pH 6.5 for experiments with EcoRI or 2-NBDG and pH 5.5 for all other experiments. All processing compartments and external environments contained $2 \mu \mathrm{M}$ BAPTA for experiments using Rhod- 2 . NBDG was used at $1 \mathrm{mM}$. Rhod-2 was used at $20 \mu \mathrm{M}$. Compartments containing EcoRI and DNA contained $400 \mathrm{U} \mathrm{mL}^{-1} \mathrm{EcoRI}, 400 \mathrm{nM}$ DNA substrate, $100 \mathrm{\mu g} \mathrm{mL}^{-1} \mathrm{BSA}$. $\beta$-galactosidase was used at 700 $\mu \mathrm{g} \mathrm{mL}-1$. Input signals were at final concentrations of 0 or $10 \mathrm{mM} \mathrm{CaCl}$ (for Rhod-2), 0 or $10 \mathrm{mM} \mathrm{MgCl}_{2}$ (for EcoRI), and 0 or $40 \mathrm{mM}$ D-lactose (for $\beta$-galactosidase) in the same buffer conditions as each external solution into which they were added.

\section{Formation of processors and processor mimics}

Chambers were formed as previously described ${ }^{21}$. After the addition of external aqueous solution to each chamber, lipid-containing oil drops $(\sim 1.5 \mu \mathrm{L})$ were formed on Teflon-coated silver wire loops, zapped with an anti-static gun, and incubated to form a monolayer for at least $5 \mathrm{~min}$. $\sim 0.5 \mu \mathrm{L}$ of each oil drop was pipetted out to reduce the drop volumes. The oil drops were then incubated for at least another 5 min.

Compartments were formed in the lipid-containing oil inside poly(methyl methacrylate) (PMMA) wells, by using a Gilson P2 pipette. 2-NBDG, $\beta$-galactosidase, Rhod- 2 compartments were formed first and incubated in the PMMA wells for at least $10 \mathrm{~min}$. EcoRI and $\alpha \mathrm{HL}$ compartments were formed later and not incubated. To make each processor, all compartments were simultaneously transferred into the oil drop using a pipette.

For processors with a molecular output, sample solution was pipetted out of each chamber before signal addition for analysis. For all processors, the total external solution after signal addition was 800 $\mu \mathrm{L}$. The processors were incubated for the specified time, at $37{ }^{\circ} \mathrm{C}$ where indicated, then sample solutions were pipetted out of each chamber again for analysis. For all processors, brightfield and or epifluorescence microscopy images were taken before and after signal addition and incubation.

\section{Fluorescence output detection and analysis}

Images for fluorescence outputs were taken using a Leica DMi8 epi fluorescence microscope. For 2NBDG, the filter cube GFP was used (ex: 450-490 nm, em: 500-550 nm), for Rhod-2 DSRED was used (ex: 540-552, em: 567-643 nm), and for EcoRI+DNA DAPI was used (ex: 325-375, em: 435-485). For quantification, the fluorescence compartments were detected and analysed on Fiji/ImageJ by a custom script followed by manual verification and, in rare cases involving artefacts caused by an air bubble or the silver wire, correction. The script applied Gaussian blur with a standard deviation of 4 and Moments automatic thresholding to each fluorescence image, then used the built-in particle analysis tool of Fiji/ImageJ to detect and record a region of interest (ROI) for each particle with an area of 20000-70000 $\mu^{2}$ and a circularity of 0.15-1.00. Each ROI was then applied to its corresponding original fluorescence image to record the average fluorescence value within the compartment area. For two-compartment processors with an EcoRI+DNA compartment, an additional ROI was defined by drawing a line across the diameter of each signal transmission compartment. The ROls were then 
applied to their corresponding fluorescence images to obtain fluorescence values across each signal transmission compartment.

\section{Glucose detection}

Glucose detection was performed using the Thermo Fisher Amplex Red Glucose/Glucose Oxidase Assay Kit according to the manufacturer's instructions. For each sample, a calibration curve with a matching buffer was used. For example, samples from a processor that received a lactose input were compared to a glucose calibration curve that also contained lactose. To avoid the non-linear range of the assay, samples with [glucose] $>30 \mu \mathrm{M}$ were diluted and re-measured.

\section{Contact angle measurements}

Contact angle measurements were obtained as described previously ${ }^{16}$. Briefly, the contact angle $(\theta)$ formed between two compartments was calculated from the radius of each compartment $\left(R_{1}, R_{2}\right)$, and the centre-to-centre distance $(L)$ by using the formula ${ }^{41}$ :

$$
2 \theta=\cos ^{-1}\left(\frac{L^{2}-R_{1}^{2}-R_{2}^{2}}{2 R_{1} R_{2}}\right)
$$

The contact angles were calculated from bright-field microscopy images using a custom-written script in MATLAB (Mathworks), which estimated the radii $R_{1}$ and $R_{2}$ of the two compartments by circle fitting and the centre-to-centre distance $L$ from the distance between the two fitted circles around the compartments. The script was also used to record the average fluorescence value within the detected compartment area.

\section{EcoRI assays}

Using a 96-well plate, $110 \mu \mathrm{L}$ reaction mixes were prepared in $91 \mathrm{mM} \mathrm{NaCl}, 91 \mu \mathrm{g} \mathrm{mL}{ }^{-1} \mathrm{BSA}$ and 45 mM MES pH 5.5 or MES pH 6.5 or Tris pH 8.0, with 0 or $10 \mathrm{mM} \mathrm{MgCl}_{2} .364$ nM DNA substrate and 364 $\mathrm{U} \mathrm{mL}^{-1} \mathrm{EcoRI}$ were used. The plate was covered and placed in a Tecan Infinite M1000 Pro microplate reader at $37^{\circ} \mathrm{C}$ and fluorescence measurements were taken from the bottom of the plate every $5 \mathrm{~min}$ with $\mathrm{ex}=645-655 \mathrm{~nm}$ and $\mathrm{em}=665-675 \mathrm{~nm}$.

\section{Data availability}

All relevant data are available from the corresponding authors upon reasonable request.

\section{References}

1. Hindley, J. W. et al. Building a synthetic mechanosensitive signaling pathway in compartmentalized artificial cells. Proc. Natl Acad. Sci. USA 116, 16711-16716 (2019).

2. Bulbake, U., Doppalapudi, S., Kommineni, N. \& Khan, W. Liposomal Formulations in Clinical Use: An Updated Review. Pharmaceutics 9, 12 (2017). 
3. Lee, Y. \& Thompson, D. H. Stimuli-responsive liposomes for drug delivery. Wiley Interdiscip. Rev. Nanomed. Nanobiotechnol. 9, e1450 (2017).

4. Rideau, E., Dimova, R., Schwille, P., Wurm, F. R. \& Landfester, K. Liposomes and polymersomes: a comparative review towards cell mimicking. Chem. Soc. Rev. 47, 8572-8610 (2018).

5. Haylock, S. et al. Membrane protein mediated bilayer communication in networks of droplet interface bilayers. Commun. Chem. 3, 1-8 (2020).

6. Lee, K. Y. et al. Photosynthetic artificial organelles sustain and control ATP-dependent reactions in a protocellular system. Nat. Biotechnol. 36, 530-535 (2018).

7. Berhanu, S., Ueda, T. \& Kuruma, Y. Artificial photosynthetic cell producing energy for protein synthesis. Nat. Commun. 10, 1-10 (2019).

8. Toparlak, D. et al. Artificial cells drive neural differentiation. Sci. Adv. 6, 4920-4938 (2020).

9. Chen, Z. et al. Synthetic beta cells for fusion-mediated dynamic insulin secretion. Nat. Chem. Biol. 14, 86-93 (2018).

10. Bayley, H., Cazimoglu, I. \& Hoskin, C. E. G. Synthetic tissues. Emerg. Top. Life Sci. 3, 615-622 (2019).

11. Maglia, G. et al. Droplet networks with incorporated protein diodes show collective properties. Nat. Nanotechnol. 4, 437-440 (2009).

12. Villar, G., Graham, A. D. \& Bayley, H. A tissue-like printed material. Science 340, 48-52 (2013).

13. Booth, M. J., Restrepo Schild, V., Downs, F. G. \& Bayley, H. Functional aqueous droplet networks. Mol. Biosyst. 13, 1658-1691 (2017).

14. Funakoshi, K., Suzuki, H. \& Takeuchi, S. Lipid Bilayer Formation by Contacting Monolayers in a Microfluidic Device for Membrane Protein Analysis. Anal. Chem. 78, 8169-8174 (2006).

15. Holden, M. A., Needham, D. \& Bayley, H. Functional Bionetworks from Nanoliter Water Droplets. J. Am. Chem. Soc. 129, 8650-8655 (2007).

16. Alcinesio, A. et al. Controlled packing and single-droplet resolution of 3D-printed functional synthetic tissues. Nat. Commun. 11, 1-13 (2020).

17. Booth, M. J., Schild, V. R., Graham, A. D., Olof, S. N. \& Bayley, H. Light-activated communication in synthetic tissues. Sci. Adv. 2, e1600056 (2016).

18. Tamaddoni, N., Freeman, E. C. \& Sarles, S. A. Sensitivity and directionality of lipid bilayer mechanotransduction studied using a revised, highly durable membrane-based hair cell sensor. Smart Mater. Struct. 24, 065014 (2015).

19. Villar, G., Heron, A. J. \& Bayley, H. Formation of droplet networks that function in aqueous environments. Nat. Nanotechnol. 6, 803-808 (2011).

20. Elani, Y., Solvas, X. C. I., Edel, J. B., Law, R. V. \& Ces, O. Microfluidic generation of encapsulated droplet interface bilayer networks (multisomes) and their use as cell-like reactors. Chem. Commun. 52, 5961-5964 (2016). 
21. Booth, M. J., Cazimoglu, I. \& Bayley, H. Controlled deprotection and release of a small molecule from a compartmented synthetic tissue module. Commun. Chem. 2, 1-8 (2019).

22. Elani, Y., Law, R. V. \& Ces, O. Vesicle-based artificial cells as chemical microreactors with spatially segregated reaction pathways. Nat. Commun. 5, 5305 (2014).

23. Asthagiri, A. R. \& Lauffenburger, D. A. Bioengineering Models of Cell Signaling. Annu. Rev. Biomed. Eng. 2, 31-53 (2000).

24. Kholodenko, B. N. Cell-signalling dynamics in time and space. Nat. Rev. Mol. Cell Biol. 7, 165176 (2006).

25. Purvis, J. E. \& Lahav, G. Encoding and decoding cellular information through signaling dynamics. Cell 152, 945-956 (2013).

26. Peng, L. et al. Memory hierarchy performance measurement of commercial dual-core desktop processors. J. Syst. Archit. 54, 816-828 (2008).

27. Elani, Y., Gee, A., Law, R. V. \& Ces, O. Engineering multi-compartment vesicle networks. Chem. Sci. 4, 3332-3338 (2013).

28. Wauer, T. et al. Construction and Manipulation of Functional Three-Dimensional Droplet Networks. ACS Nano 8, 771-779 (2014).

29. Elani, Y., Law, R. V. \& Ces, O. Vesicle-based artificial cells as chemical microreactors with spatially segregated reaction pathways. Nat. Commun. 5, 1-5 (2014).

30. Dupin, A. \& Simmel, F. C. Signalling and differentiation in emulsion-based multicompartmentalized in vitro gene circuits. Nat. Chem. 11, 32-39 (2019).

31. Pingoud, V. et al. On the Divalent Metal Ion Dependence of DNA Cleavage by Restriction Endonucleases of the EcoRI Family. J. Mol. Biol. 393, 140-160 (2009).

32. Yang, C. J., Li, J. J. \& Tan, W. Using molecular beacons for sensitive fluorescence assays of the enzymatic cleavage of nucleic acids. in Methods in Molecular Biology vol. 335 71-81 (Humana Press Inc., Totowa, NJ, 2006).

33. Crisalli, P. \& Kool, E. T. Multi-path quenchers: Efficient quenching of common fluorophores. Bioconjugate Chem. 22, 2345-2354 (2011).

34. Marras, S. A. E. Selection of fluorophore and quencher pairs for fluorescent nucleic acid hybridization probes. in Methods in Molecular Biology vol. 335 3-16 (Humana Press Inc., Totowa, NJ, 2006).

35. Walker, B., Kasianowicz, J., Krishnasastry, M. \& Bayley, H. A pore-forming protein with a metal-actuated switch. Protein Eng. Des. Sel. 7, 655-662 (1994).

36. Braha, O. et al. Designed protein pores as components for biosensors. Chem. Biol. 4, 497-505 (1997).

37. Chang, C. yu, Niblack, B., Walker, B. \& Bayley, H. A photogenerated pore-forming protein. Chem. Biol. 2, 391-400 (1995).

38. Bayley, H. Pore-Forming Proteins with Built-in Triggers and Switches. Bioorg. Chem. 23, 340354 (1995). 
39. Koo, S., Cheley, S. \& Bayley, H. Redirecting Pore Assembly of Staphylococcal $\alpha$-Hemolysin by Protein Engineering. ACS Cent. Sci. 5, 629-639 (2019).

40. Hammerstein, A. F., Jayasinghe, L. \& Bayley, H. Subunit dimers of $\alpha$-hemolysin expand the engineering toolbox for protein nanopores. J. Biol. Chem. 286, 14324-14334 (2011).

41. Dixit, S. S., Pincus, A., Guo, B. \& Faris, G. W. Droplet shape analysis and permeability studies in droplet lipid bilayers. Langmuir 28, 7442-7451 (2012).

\section{Acknowledgements}

This research was supported by a European Research Council Advanced Grant. I.C. acknowledges funding by the University of Oxford, the EPSRC \& BBSRC Centre for Doctoral Training in Synthetic Biology (grant EP/L016494/1), the Clarendon Fund Scholarship, and the Oxford-Broomhead Graduate Scholarship. M.J.B. acknowledges funding by a Royal Society University Research Fellowship. The authors thank Dr Alessandro Alcinesio for insightful discussions, contact angle analyses and assistance with fluorescence microscopy.

\section{Author Information}

\section{Affiliations}

Department of Chemistry, University of Oxford, Chemistry Research Laboratory, 12 Mansfield Road, Oxford, OX1 3TA, UK

Idil Cazimoglu, Michael J. Booth, Hagan Bayley

\section{Contributions}

I.C., M.J.B. and H.B. conceived the experiments. I.C. conducted the experiments, collected the data and performed the analyses. I.C., M.J.B. and H.B. wrote the paper.

\section{Corresponding authors}

Correspondence to Hagan Bayley or Michael Booth.

\section{Competing interests}

The authors declare no competing interests. 